\title{
TENDÊNCIA ATUALIZANTE EM ELIZABETH HARMON PERSONAGEM DA MINISSÉRIE O GAMBITO DA RAINHA NA PERSPECTIVA DA ABORDAGEM CENTRADA NA PESSOA
}

\author{
UPDATING TREND IN ELIZABETH HARMON CHARACTER FROM THE MINISSERIES \\ THE QUEEN'S GAMBITO FROM THE PERSPECTIVE OF PERSON-CENTERED \\ APPROACH
}

\author{
Cleimara Cabral Dutra Boscariol ${ }^{1}$ \\ Luzia de Miranda Meurer ${ }^{2}$
}

RESUMO: Este estudo descreve a história de vida e carreira enxadrista de Elizabeth Harmom personagem da minissérie O Gambito da Rainha. Com o objetivo em desvelar o sentido do jogo de xadrez na manifestação da Tendência Atualizante, um dos conceitos centrais da Abordagem Centrada na Pessoa. Para desenvolver o objetivo, realizou-se uma interlocução entre a teoria da personalidade, Tendência Atualizante, criatividade e a minissérie. $\mathrm{Na}$ coleta de informações foram consideradas as cenas centradas nas narrativas da história de vida e as ações da personagem Beth. Para a análise e discussão dos resultados, elaborou-se duas unidades temáticas. A primeira refere-se à fase infantil, em que Beth passa a morar em um abrigo, onde aprende a jogar xadrez, e na adolescência é adotada, iniciando em torneios profissionais, na segunda análise refere-se ao início da sua fase adulta com dependência de bebidas alcoólicas, comprometendo a sua carreira de enxadrista. Os resultados apresentam como o jogo de xadrez se tornou uma possibilidade para Beth e a Tendência Atualizar-se em resposta às adversidades vividas ao encontro de uma regulação organísmica para a sua vida.

Palavras-chave: Abordagem centrada na pessoa. Tendência atualizante. Criatividade. Jogo de xadrez.

ABSTRACT: This study describes Elizabeth Harmon's life story and career of Elizabeth Harmon's character from the miniseries The Queen's Gammon. The objective was to discover the meaning of the chess game in the manifestation of the Updating Trend, one of the central concepts of the Person-Centered Approach. An interlocution was made between personality theory, updating trends, creativity, and miniseries to develop the objective. For the information collection, it was considered the scenes centered on the narratives of the life story and the actions of the character Beth. For the analysis and discussion of the results, two thematic units were elaborated: the first refers to the childhood phase, in which Beth begins to live in a shelter, where she learns to play chess, and in her adolescence is adopted, starting in professional tournaments, in the second analysis refers to the beginning of her adult phase with alcohol dependence, compromising her career as a chess player. The results present how the chess game has become a possibility for Beth and the Tendency to update themselves in response to the adversities experienced in meeting an organizational regulation for her life.

Keywords: Person centered approach. Updating trend. Creativity. Chess game.

\footnotetext{
${ }^{\text {I }}$ Acadêmica do curso de Psicologia da UNIFEBE.E-mail: cleimaracdb@gmail.com

${ }^{2}$ Professora do Curso de Psicologia da UNIFEBE e orientadora deste estudo. Graduada em Psicologia pela Universidade Federal de Santa Catarina - UFSC e Mestra em Educação pela Universidade Regional de Blumenau - FURB. E-mail: luzia.meurer@unifebe.edu.br
} 


\section{INTRODUÇÃO}

Neste trabalho desenvolveu-se um estudo da minissérie $O$ Gambito da Rainha, baseada no livro de Walter Tevis, publicado em 1983, de gênero dramático produzida por Scott Frank e Allan Scott e lançada pela Netflix, em 2020. A história retrata as fases de desenvolvimento humano da personagem Elizabeth Harmon, que aos 9 anos de idade sofre um trágico acidente de carro, no qual a mãe dela vem a óbito. Beth sobrevive, porém é levada a morar em um abrigo, o Lar Methuen, no estado do Kentucky, nos Estados Unidos. Lá, desenvolve dependência de tranquilizantes, que eram administrados pela equipe da instituição, para as crianças naquela época. Enquanto vivia no abrigo, teve a curiosidade de aprender a jogar xadrez. Shaibel, que era o zelador, deu-lhe aulas e instruções, e Beth se torna uma criança prodígio no jogo de xadrez.

Quando adolescente é adotada pelo casal Wheatley, e busca oportunidades de participar de torneios de xadrez. Sua mãe adotiva Alma, a inscreve em importantes campeonatos. Beth vence todos, conquistando um espaço feminino em torneios predominantemente ocupados por homens. Mas no início da sua fase adulta, o abuso de bebidas alcoólicas e novamente o contato com os tranquilizantes a faz perder a concentração nas grandes competições e se afasta dos principais torneios. Diante da sua história de vida e do aprendizado com o jogo de xadrez Beth internaliza algumas lembranças e narrativas para encontrar o seu lugar no mundo.

Os aspectos da história de vida da personagem vêm ao encontro da Tendência Atualizante pressuposto teórico da Abordagem Centrada na Pessoa (ACP), parte do princípio de que todos os seres humanos se movem em direção ao crescimento e atualização. Rogers (I986) sustenta que há uma capacidade fundamental do ser humano, à sua tendência a atualizar-se na qual se sente estimulado a se mover em direção a algo. Independentemente das circunstâncias serem propícias ou não, as ações de um organismo estarão sempre no sentido de desenvolvimento de si mesmo.

$\mathrm{Na}$ minissérie, Beth opera em busca pela regulação organísmica ou, pode-se dizer, a atualização que envolve o indivíduo como um todo, nas suas esferas psicológica e emocional, assim como consciente e inconsciente. Em sua história acompanha-se um dos importantes eventos da sua vida, a descoberta do jogo de xadrez. Nesse cenário, este estudo tem o objetivo em desvelar o sentido do jogo do xadrez na manifestação da Tendência Atualizante na vida de Elizabeth Harmon. Assim, levantou-se a questão para esta pesquisa: Que aspectos do desenvolvimento humano da personagem são congruentes com a manifestação da Tendência Atualizante? Tal questionamento é o que move e direciona este estudo, sustentado e permeado na perspectiva da Abordagem Centrada na Pessoa.

\section{REFERENCIAL TEÓRICO}

\section{I A abordagem centrada na pessoa e a teoria da personalidade}

A Abordagem Centrada na Pessoa está inserida nas correntes fenomenológicas, existencialistas e humanistas da psicologia. Seu precursor teórico Carl Rogers sustenta a 
perspectiva de que todo indivíduo possui um núcleo básico da personalidade humana com tendência à saúde e ao crescimento. Os aspectos psicológicos são entendidos como fenômenos, no qual trabalha a ideia do que foi experenciado pelo indivíduo. Nesse sentido, Holanda (2009a) destaca que a ACP é uma abordagem para a vida e de todas as formas de ser, podendo estar presente na psicoterapia, na educação, e em tudo que diz respeito às relações humanas.

No que diz respeito às relações humanas, Rogers (2009) explana que os indivíduos estão em busca por objetivos de vida, e por questões que qualquer homem põe a si mesmo. Ás vezes de maneira calma e meditativa, outras vezes na agonia da incerteza e do desespero. Para Rogers (2018), a capacidade de prestar atenção consciente é uma das mais recentes etapas evolutivas do ser humano. Enfatiza Feijoo (200o), que a consciência do eu aparece como uma atividade e quando a interioridade não equivale à consciência do eu, constata-se uma carência expressada pela angústia de se conquistar tal consciência. A essa desadaptação psicológica Rogers (1987) comenta ser oriunda do desacordo vivido pelo indivíduo entre o eu e a sua experiência. Relata que cada indivíduo reage à realidade conforme a percepção que tem. Segundo, Holanda (2009b), o desvelar dos sentidos ocorre naquilo que o mundo se apresenta para uma consciência, no qual o fenômeno é dotado de um conjunto de significados.

Do ponto de vista rogeriano as pessoas tendem a se desenvolver positivamente, mas diante das circunstâncias adversas da vida podem existir dificuldades ao crescimento psicológico quando um indivíduo experimenta incongruência, defesas e desorganização. Roger aborda a teoria da personalidade em alguns conceitos-chave conforme Feist et al. (2015), conceitos: a) tendência à atualização na qual há a pré-disposição para a pessoa mover-se de uma forma que a torne funcional; b) um indivíduo se torna uma pessoa ao fazer contato com um cuidador cuja consideração por ele promova uma autoconsideração positiva; c) existem obstáculos ao crescimento psicológico, quando se experimenta condições de incongruências, defesas e desorganização; d) a incongruência e defesas levam o indivíduo a uma avaliação externa, sentindo vulnerabilidade, ansiedade e ameaça; e) quando incongruentes, as pessoas tornam-se defensivas; $f$ ) o processo de mudança da personalidade ocorre desde o uso extremo de defesas, ou uma relutância de falar de si até um estágio final, no qual os indivíduos se tornam congruentes e abertos a experiências, sem a necessidade de serem defensivos.

Indivíduos em estado de congruência, segundo Rogers (2018), terão maior consciência de suas emoções podendo ser essas expressas ou não. Já na incongruência o indivíduo tende a negar seu sentimento à consciência, ocorrendo uma distorção da sua percepção. Visto que para Feit et al. (2015), a congruência envolve sentimentos, consciência e expressão, e a incongruência é o surgimento de um ou dois pontos que divergem dessas três experiências, podendo ocorrer um rompimento entre sentimentos e consciência. Os autores comentam um exemplo, quando uma pessoa se sente com raiva, esta pode ser percebida para os outros, porém a pessoa com raiva não está necessariamente consciente do seu sentimento.

A raiva é uma emoção expressada em uma ação geralmente de defesa física ou psicológica. Ekman (2orI) comenta que a raiva é uma emoção que abrange diversas experiências e raramente é isolada de outros sentimentos e muitas vezes o medo precede à raiva. Indivíduos que demonstram em seu comportamento sentimentos de raiva, segundo Ekman (20II) informam aos outros a respeito de um problema, associado aos sentimentos de 
angústia. Na perspectiva da ACP Rogers (2009) descreve as angústias como fachadas de um modo de expressão da personalidade com características que os indivíduos mostram para se fechar, afastar-se, com hesitações de um eu que não se é.

Como apresentado anteriormente, mesmo os indivíduos tendo a tendência a desenvolver-se positivamente, podem experimentar processos de desorganização com suas emoções e sentimentos. É preciso reconhecer segundo Rogers (2018), nos níveis psicológicos podem surgir as dificuldades da personalidade nas quais o indivíduo se vê em situações de ameaças, desenvolvendo mecanismos de defesa. Já indivíduos com abertura às experiências irão descobrir aspectos ocultos de si mesmo que negou a consciência, podendo passar por momentos difíceis ou ansiosos até que sejam assimilados a uma autoimagem revista e modificada, com base nisso se pode ponderar equilíbrio por meio das ações. $\mathrm{O}$ mesmo autor considera que os indivíduos desenvolvem em direção a uma congruência, entre seu organismo self ${ }^{3}$ que sente e seu conceito de si. O self na visão rogeriana, explanam Maia et al. (2009), é uma condição consciente e reflexiva de si, que possui e fornece significados com os quais a pessoa se identifica e a partir dos quais percebe a realidade.

\subsubsection{A Tendência Atualizante compreendida pela ACP como capacidade do indivíduo em se (re)organizar (re)estruturar}

A Tendência Atualizante é um pressuposto de que todos os seres humanos se movem em direção à conclusão ou à realização dos seus potenciais. Enfatiza Rogers (2018), tal tendência é manifestada nos indivíduos para serem capazes de resolver seus próprios problemas, compreender a si mesmo e alcançar um funcionamento interno mais adequado. Feist et al. (2015) consideram a Tendência Atualizante relacionada às necessidades de aperfeiçoamento, expressas de várias formas, nelas incluem: curiosidade, alegria e autoexploração. Para os mesmos autores, as pessoas têm dentro de si a força criativa para resolver situações que julgam problemáticas, podendo alterar seu autoconceito e se tornar cada vez mais autodirecionada.

A autodireção é uma tendência positiva da experiência do indivíduo. Rogers (2009) explana, quando os indivíduos vivenciam mudanças significativas, expressando sentimentos e experimentando uma maior diferenciação deles, optam por objetivos no qual pretende atingir, sendo capazes de avaliar e decidir por seus comportamentos. Rogers (2009, p. 196) aponta que implica "ser o que realmente se é [...] a tendência do indivíduo para viver uma relação aberta, amigável e estreita com a sua existência". Mas por outro lado, o mesmo autor ressalta que não necessariamente isso aconteça com certa facilidade, muitas vezes quando o indivíduo se percebe de uma nova faceta sua inicialmente a rejeita. E a abertura da experiência ocorrerá quando em um aspecto da sua vivencia até então negado, por meio de um clima de aceitação, poderá tentar assumir a experiência como parte de si.

Os princípios da Tendência Atualizante referem-se ao potencial humano e, proporcionadas certas condições facilitadoras o indivíduo tende a ampliar seu repertório

\footnotetext{
${ }^{3}$ Self: autoconceito e de noção de eu, é a percepção de si e da realidade pela própria pessoa.
} 
interno, buscando novas maneiras de se adaptar ao meio. Para que isso ocorra, Rogers (1992) descreve que de alguma forma, os facilitadores (pais, professores, apoiadores e psicoterapeutas) possam empregar atitudes básicas e necessárias. Essas atitudes, segundo Rogers (1992) são: a compreensão empática em que o facilitador observa e compreende o que o outro busca seus motivos, medos e sentimentos. A outra atitude é a congruência, nesta o facilitador será autêntico tanto nos seus sentimentos quanto em suas percepções em relação à pessoa que busca ajuda. A terceira é a atitude de consideração positiva, na qual o facilitador desenvolve a capacidade de aceitar o outro, entendendo que o outro está em busca de sentir-se bem e se encontrar no mundo.

No que diz respeito aos facilitadores, Rogers (2018) enfatiza que oferecerem recursos de aprendizagem, de suas próprias experiências, de livros ou de outros materiais. Nessa mesma linha de consideração, Rogers (2018) comenta sobre a aprendizagem significativa, sendo aquela que provoca uma modificação, seja no comportamento do indivíduo ou na orientação de uma ação futura. Para Chaves e Mendonça (1997) é compreendida pela interação entre conhecimentos prévios e conhecimentos novos, os quais o indivíduo adquire significado no nível da consciência. A aprendizagem significativa pode ser profunda, quando não se limita somente a um aumento de conhecimento, e sim estando relacionada à existência. Destaca Rogers (2009), que a pessoa começa a se ver de modo diferente, aceita-se e aceita seus sentimentos de uma maneira mais completa. Feits et al. (2015) assimilam experiências ao self no nível simbólico, com maior efetividade na solução de problemas, desenvolvendo autoconsideração positiva consigo mesma.

\subsubsection{A criatividade como manifestação da Tendência Atualizante}

A ACP compreende a criatividade como uma capacidade intrínseca ao ser humano em formular e reformular soluções diante das adversidades. Aponta Roger (2009), que há várias maneiras de definir a criatividade, uma delas é o processo criativo em que se trata de uma emergência na ação de um novo modo relacional que provém da natureza única do indivíduo, sejam em uma ação material, acontecimentos, pessoas ou circunstâncias da vida. $\mathrm{O}$ mesmo autor explana que as condições internas da criatividade estão associadas às potencialidades, e relata sobre a abertura à experiência nomeando extensionalidade ${ }^{4}$, sendo uma condição que se opõe à defesa psicológica.

Quanto mais contato o indivíduo tiver com as suas experiências em nível da sua compreensão, sustenta Rogers (2009), mais seguro poderá estar de que a sua criatividade irá ser pessoal e construtiva. No entanto, na descrição dos aspectos dos atos criativos, Roger (2009) cita concomitante a angústia em indivíduos que estão isolados como uma experiência que acompanha a criatividade, havendo o desejo de comunicar o seu ato criativo, como uma forma de acalmar a angústia, muitas vezes proveniente do isolamento. $O$ mesmo autor relaciona o processo criativo e o comportamento criativo como uma maneira de adaptação ao mundo para sobreviver.

\footnotetext{
${ }^{4}$ Extensionalidade: se refere à definição da identidade.
} 
A criatividade, segundo Rogers (2018) aparenta ser a tendência do homem para se realizar. Destaca o autor ser uma exploração do espaço interno, área do indivíduo, do psiquismo, do espaço interior que se move em direção a uma aprendizagem não basicamente cognitiva, que geralmente parece ilógica e irracional. $O$ autor faz referência à existência de capacidades e potenciais da psique ilimitada e relata parecer óbvio exemplo, que um indivíduo que flutua num tanque de água morna, sem qualquer estimulação visual, auditiva e tátil, gustativa ou olfativa, não estará experimentando nada. E o que acontece é que um indivíduo nessas condições está passando por ricas imagens visuais, por sons imaginários e todo tipo de experiências, vindas de fontes desconhecidas de estimulação interna. Parece que no mundo interior está sempre ocorrendo algo que absolutamente não se conhece (ROGERS, 2018).

Por sua vez, o método fenomenológico de investigação no que se refere ao espaço interno do indivíduo, Giogio e Souza (2010) mencionam que consiste em não realizar reivindicações, mas redução fenomenológica. Ou seja, a realidade do objeto da descrição, para os autores não é necessariamente o centro da questão, e sim o que se deve considerar é o modo como o objeto se apresenta, o que descreve a experiência. Assim, na investigação de um processo criativo, os autores recomendam o método fenomenológico como maneira de acessar o mundo interno do indivíduo, que descreverá o que foi experenciado. Em corroboração a essa ideia o filósofo existencialista Jean Paul Sartre também recomenda esse método. Sartre (2012) diz que se deve estudar as possibilidades dos fenômenos psicológicos, por exemplo, a imaginação. Investigar como a estrutura da realidade humana torna possível a imaginação e de que forma a torna possível. Ao referir-se a tal assunto, Sartre (2019) comenta sobre a consciência estabelecer uma relação a um objeto existente, e quando o objeto é tomado como abstrato apreendido fora do contexto isso significa abstrair.

Outro aspecto levantado é a motivação para a criatividade, reforça Rogers (2009), é a causa principal de uma tendência que o indivíduo descobre em um nível mais profundo ou do seu eu. Essa tendência muitas vezes considerada pelo autor pode estar enterrada nas camadas psicológicas defensivas e escondida por fachadas elaboradas que negam a sua existência. $\mathrm{O}$ autor acredita que a Tendência Atualizante existe em todos os indivíduos, e está apenas à espera das condições adequadas para se exprimir e se manifestar, interagindo de modo mais harmônico com o meio.

E para ocorrer essa interação harmoniosa com o meio Rogers (2009) relaciona com as condições psicológicas de segurança e de liberdade na facilitação da criatividade construtiva. $\mathrm{Na}$ segurança psicológica destaca a atitude de aceitação do indivíduo como um valor incondicional, em que um professor, pai ou terapeuta ou qualquer outra pessoa com uma função de facilitar, atribui que o indivíduo possui um valor específico e original. Dessa forma, essa condição presente, segundo o mesmo autor favorece a criatividade, e o indivíduo envolvido nessa atitude, sente-se em um clima de segurança, sem uma avaliação de atmosfera de julgamento. Reforça Rogers (2009, p. 415), “a avaliação é sempre uma ameaça, cria sempre uma necessidade de defesa, significa sempre que uma determinada parte da experiência deve ser negada a consciência”. Na liberdade psicológica, Rogers (2009) considera que o indivíduo experimenta a liberdade de expressão simbólica favorecendo a criatividade. Essa liberdade 
para o indivíduo permite horizontes para pensar, sentir, ser o que é no mundo mais íntimo, favorecendo a abertura e espontaneidade de associar percepções, conceitos e significados.

2.2 $\mathrm{O}$ jogo de xadrez e o lance do gambito da rainha contribuindo como uma possibilidade da tendência atualizante

O jogo de xadrez é praticado por dois jogadores sobre um tabuleiro de 64 casas, encenando um conflito entre dois exércitos, cada um composto de 16 peças, que se movem no tabuleiro, em uma disputa que exige raciocínio e estratégia. $O$ jogo, conforme destaca Sesi (2012), surgiu na Índia séc. IV, seu nome de origem é Chaturanga, um adjetivo sânscrito que faz referência as quatro classes de forças que compunham um exército: a infantaria (os peões), a cavalaria (os cavalos), a elefantaria (as torres) e os carros (bispos). No início das civilizações, enfatiza Huizinga (2018), a rivalidade era um fator enobrecedor, na qual as formas culturais se desenvolveram em aspectos de competições sagradas, e nesse sentido, a estrutura de sociedade se expande. Filguth (2007) destaca que no jogo se encontram sutilezas culturais, tais como o símbolo e a representação do lúdico na sociedade. Considerado de natureza esportiva e recreativa, Capablanca (1972) diz que o jogo de xadrez é mais do que uma diversão intelectual, ele serve para distrair e esquecer, momentaneamente, as angústia e preocupações.

Referente à história do jogo de xadrez, Capablanca (1972) retrata que a peça Rainha existia com outro nome, porque no Oriente, as mulheres não jogavam e não tinham, geralmente, papel importante. Assinala Santos (2010), que na origem do jogo de xadrez, o lugar da Rainha era ocupado pelo conselheiro real. E foi durante a idade média, na Europa, que a Rainha lentamente substituiu seu antecessor. Nessa mesma linha de consideração, Capablanca (1972) comenta que o jogo quando chegou à Europa, a peça Rainha ocupou posição de destaque com movimentações estratégicas, e um dos lances mais admirável é o da habilidade de abertura para fazer um ataque conhecido como o Gambito da Rainha. É um lance de movimento estratégico e de inteligência, que força o adversário a ficar em uma posição mais defensiva, em desvantagem, no qual o adversário terá menos probabilidade de formular um ataque.

$\mathrm{Na}$ contemporaneidade o jogo de xadrez é considerado uma modalidade esportiva pelo Comitê Olímpico Internacional desde 200I. Revisitando os fatos históricos de campeonatos, encontra-se que o jogo de xadrez foi a única modalidade em que uma mulher conseguiu vencer um torneio contra homens. Judit Polgar, em 1988, conquistando o título de campeã mundial em Timișoara na Romênia (SESI, 2012).

Dadas às dificuldades expostas na inserção da figura feminina, em decorrência de um contexto sócio-histórico-cultural, o qual a afastava de conceitos estratégicos que demandavam inteligência. Natalie Rogers em seu livro A Mulher Emergente, publicado em 1987, retrata a imposição de papéis para a mulher e a consequência de uma dependência masculina. Rogers (1987) considera que a mulher, se for de vontade própria, deve assumir a responsabilidade pela vida, já que possui a capacidade de gerar e planejar. A autora ressalta que embora haja indivíduos que tentam intimidar ou derrubar a figura feminina, será ela (a mulher) que irá 
permitir que isso aconteça, e quando conscientes das suas reações e de seus sentimentos se tornam mais capazes de cuidar de si mesma e de lutar de maneira construtiva.

Sobre as tomadas de decisões e o pensamento estratégico em um jogo de xadrez, pode-se associá-las segundo Filguth (2007, p. 133), "as tomadas de controle, não só sobre os adversários e sobre um território, mas também sobre si mesmo, sobre o próprio eu". Para o mesmo autor, os jogadores desenvolvem pensamentos mais elevados porque analisam ações $\mathrm{e}$ consequências. Nesse sentido, Regitan (2021) ressalta que o jogo promove trabalhar a imaginação e visualização, desenvolvendo inteligência espacial, considerada uma capacidade de entender o mundo de forma tridimensional, física e mental. $O$ indivíduo que desenvolve essa capacidade pode perceber cenários reais e imaginários e, por meio dessa capacidade, interage com o que é externo, cria e pode ser capaz de pensar estrategicamente e com lógica.

Assim, a relação do jogo de xadrez com a Tendência Atualizante é conforme a compreensão do jogo se amplia, possibilitando ao jogador mover as peças em um movimento diferente do pensamento anteriormente criado, visualizam-se possibilidades futuras, desenvolvendo a imaginação e a criatividade, porque há uma infinidade de combinações a serem construídas para além das estratégias cognitivas.

\section{PROCEDIMENTOS METODOLÓGICOS}

O método desta pesquisa retrata a maneira de pensar para se chegar à natureza de um determinado fenômeno. Segundo Flick (2013), o método é baseado no uso de categorias derivadas de modelos teóricos. Para desenvolver este trabalho o procedimento da pesquisa foi resgatar o histórico de vida da personagem Elizabeth Harmon, por meio das narrativas que a minissérie destaca, possibilitando realizar a discussão dos achados, interpretação dos dados e apresentação dos resultados.

A pesquisa foi de natureza básica com abordagem qualitativa, caracterizada do tipo narrativa, a qual o pesquisador, segundo Sahagoff (2015), desenvolve uma seleção de materiais que vão ao encontro de sua pesquisa entendida como uma maneira de compreender a experiência humana. Dessa forma, na pesquisa narrativa o papel do pesquisador é interpretar os dados obtidos e coletados de forma oral ou escrita.

Para a coleta de informações relevantes da minissérie, que é composta de sete episódios que totalizam 395 horas de conteúdo audiovisual, considerou-se as cenas centradas nas memórias e ações da personagem Beth. Realizaram-se registros de cenas selecionadas, utilizando como método o protocolo guia que se encontra no apêndice A deste trabalho. Segundo Penafaria (2009) analisar um filme pode ser uma característica de interpretação de conteúdo, não existe uma metodologia universal, e a análise implica duas etapas: descrever e, em seguida, estabelecer e compreender as relações entre os elementos descritos, ou seja, interpretá-los. Assim, a proposta de análise temática de um filme ou minissérie, permite ver mais e ouvir mais, como experiência dos sentidos.

No processo de análise, ocorreu a discussão dos achados e de suas interpretações. Os dados foram analisados com base na análise temática, configurada como um método qualitativo de análise de dados encontrados em uma pesquisa. Consiste em, fundamentado no 
estudo, identificar quais foram os conteúdos ou fenômenos que emergiram, realizando uma análise interpretativa deles (SOUZA, 2019). Por meio da pergunta de pesquisa e do material coletado, previamente selecionado com base nos critérios citados, estabeleceu-se os temas que apresentam a manifestação da Tendência Atualizante agindo na vida da personagem. A estratégia para descrever o fenômeno da Tendência Atualizante foi estruturá-lo e organizá-lo de maneira sintética para a análise temática, utilizou-se de mapas conceituais, com o objetivo de apresentar as informações e características do fenômeno achado para a construção e produção da análise. Conforme se apresentam nas Figuras i e 2, a seguir.

Figurar- Mapa conceitual - Aspectos Psicológicos

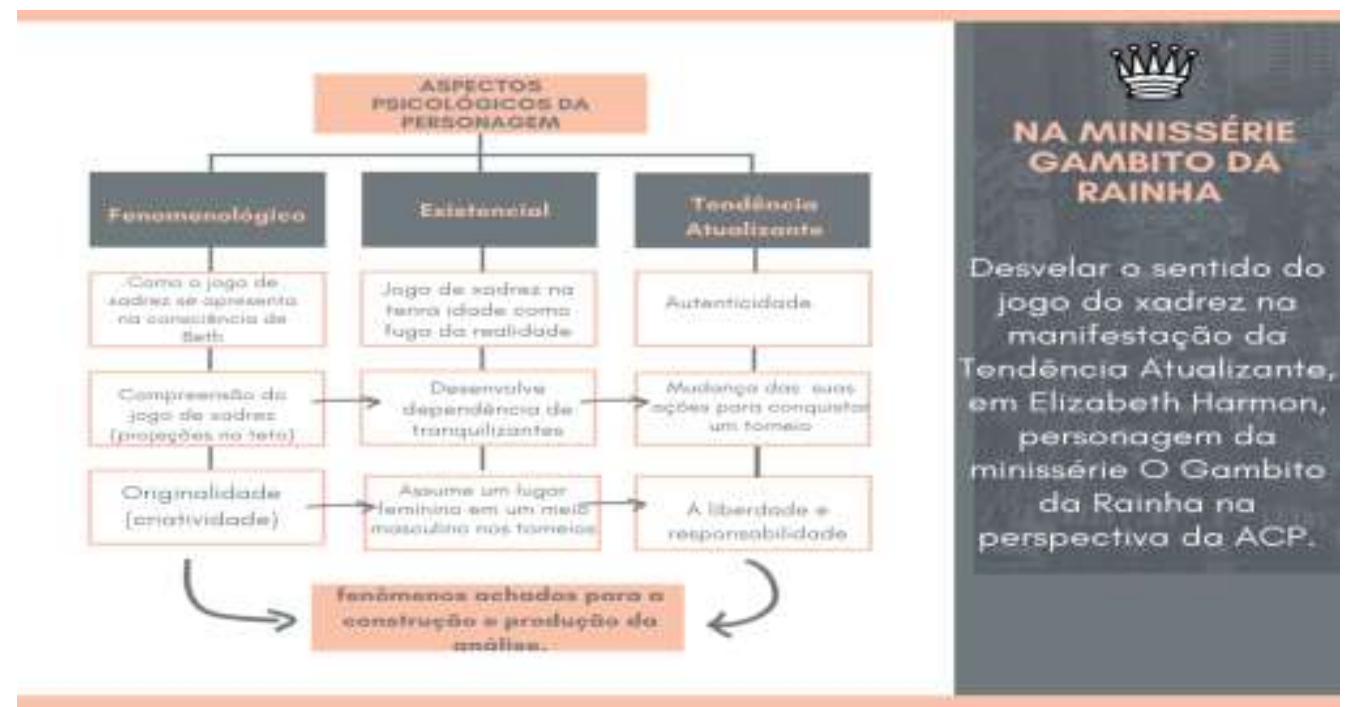

Fonte: elaborado pelas autoras (2021).

Figura 2 - Mapa conceitual - Temas Elaborados

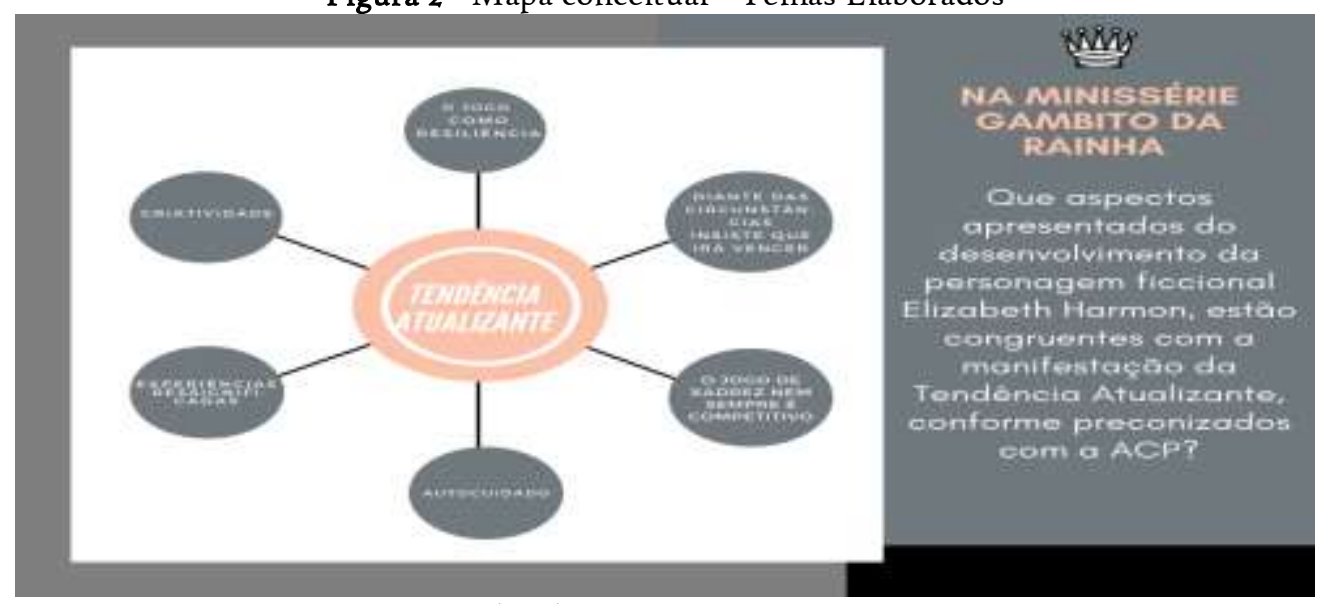

Fonte: elaborado pelas autoras (2021). 


\section{ANÁLISE DOS RESULTADOS}

$\mathrm{Na}$ busca do objetivo deste estudo, realizou-se a análise dos aspectos psicológicos da personagem Elizabeth Harmon, valendo-se das cenas apresentadas pela minissérie, as quais Beth, por meio de suas lembranças, realiza um resgate de narrativas, assim, foi possível conhecer a história de vida e carreira da enxadrista. Nessa perspectiva, convencionou realizar duas unidades de análises para descrever o pressuposto da Tendência Atualizante manifestado na vida de Beth.

A primeira trata-se de aspectos que ocorreram na fase infantil e adolescência. Dessa maneira, elaborou-se os temas: a) o jogo como resiliência; b) diante das circunstâncias insiste que irá vencer; c) o jogo de xadrez nem sempre é competitivo e d) saber se cuidar (autocuidado). Na segunda unidade, apresentou-se a personagem no início da sua fase adulta e com carreira enxadrista. Os aspectos identificados coerentes com a manifestação da Tendência Atualizante se tratam dos temas: e) experiências ressignificadas e f) criatividade.

A história se inicia com Beth na França, atrasada para a final de uma partida de jogo de xadrez. Chegando ao local senta-se para jogar, olhando para o seu adversário, começa a resgatar lembranças e narrativas internalizadas de pessoas que fizeram parte da sua história de vida até aquele momento. Lembra-se da cena e o motivo pelo qual ficou sozinha aos 9 de idade, após um acidente de carro. Momentos antes do acidente sua mãe recorreu ao seu pai, fazendo um pedido de ajuda nos cuidados parentais, ao qual ele ignorou. $O$ acidente ocorre devido à sua mãe Alice Harmon, intencionalmente, colidir com um veículo que se aproximava. Alice falece, e Beth sobrevive. Por causa disso, é levada para morar em um abrigo, o Lar Methuen, no final dos anos 1950.

No abrigo, Beth vivia calada e retraída, recebe tranquilizantes, administrados com permissão Legal do governo da época. Em seu novo lar, encontra no porão, o zelador Shaibel, sozinho jogando xadrez. Ela tem a curiosidade em aprender sobre jogo, o qual observa com atenção aos movimentos das peças feitos no tabuleiro. Em uma das suas idas ao porão, Beth pede para jogar com Shaibel, ele a chama de criança e diz que não é um jogo para meninas.

Após alguns dias, ela retorna ao porão e mais encorajada insiste: "O senhor pode me ensinar, eu já sei um pouco só de ficar olhando" (SIC) 5 . Antes de dormir, Beth imaginava no teto do seu quarto, o tabuleiro de xadrez, e mentalmente movimentava as peças. Desse modo, demonstra para Shaibel que já compreendia um pouco sobre o jogo. Ele a deixa jogar e passa a instruí-la, com os nomes das peças, posições e estratégias específicas do jogo. Beth frequentemente vai ao porão encontrar-se com Shaibel, aumentando, assim, o seu aprendizado.

Desse modo, inicia-se a primeira unidade da análise. Identifica-se em Shaibel o papel de facilitador no processo de aprendizagem de Beth com o jogo. Notam-se algumas das atitudes facilitadoras dele, a compreensão empática mesmo de início, demonstrando resistência, compreende a curiosidade de Beth em aprender a jogar xadrez. Shaibel também é

5 (SIC) é um advérbio latino que em português significa "assim”, “desse modo”, "exatamente assim”. 
congruente ao ensiná-la, há por ele a atitude de consideração positiva de que Beth necessitava, nota-se que ela de alguma maneira sente-se aceita e acolhida no porão jogando xadrez.

É possível dizer que a Tendência Atualizante está manifestando em Beth por meio do jogo, como uma forma que ela encontrou de suportar a sua realidade (perda da mãe e morar em um abrigo). Conforme estabelecido o tema: a) resiliência por meio do jogo. Considera-se que Beth ao jogar xadrez, parecia sair do seu estado de letargia, possibilitando não pensar nas suas experiências dolorosas e não assimiladas na sua consciência. Assim, Capablanca (1972) diz que jogar xadrez permite às pessoas uma maneira de se distrair e esquecer momentaneamente suas angústias e preocupações.

Beth vivia isolada da convivência com as outras meninas e aprendeu a ingerir as pílulas tranquilizantes à noite, quando estava em silêncio no quarto compartilhado. Parece que Beth acreditava que as pílulas a auxiliaria a aguçar a sua imaginação/criatividade, que aparentemente para ela era uma tentativa de projetar visualmente o tabuleiro de xadrez no teto do seu quarto. Desse modo, concentrava-se e, por meio da sua imaginação, desenvolvia a habilidade de movimentar mentalmente as peças do jogo que havia observado. Assim, pode-se dizer que Beth, por meio do jogo de xadrez, estava desenvolvendo a inteligência espacial com a capacidade de imaginá-lo e visualmente projetá-lo no teto. Devido à ausência do objeto físico (o tabuleiro e as peças) Beth usa a sua criatividade para interagir com o jogo. Conforme Regitan (2021), Beth estava construindo inúmeros processos cognitivos, tal como a criatividade.

A respeito dos tranquilizantes geralmente são utilizados para sedação, pertence à classe dos benzodiazepínicos, os quais potencializam a ação gabaérgica ${ }^{6}$ no SNC. Reduz a estimulação cerebral, diminui a ansiedade, promove relaxamento muscular, sonolência, dentre outros efeitos (ZORZANELLI et al., 2019). Porém, diferentemente do que a personagem Beth acreditava, tais substâncias causam prejuízos à memória, produzem inclusive amnésia anterógrada, ou seja, não há aprendizado sob o efeito dessas substâncias. No entanto, deve-se enfatizar que tais substâncias ao diminuírem a ansiedade, é possível que favoreciam o raciocínio e a liberdade de criação na mente de Beth, uma vez que sob estresse e estímulo adrenérgico, o indivíduo apresenta alterações cognitivas e comportamentais, agindo principalmente por impulsividade (SILVA; TORRES, 2020).

Referente ao isolamento da personagem considera-se uma experiência que acompanha a criatividade. De acordo com Rogers (2009), a criatividade pode emergir em momentos nos quais o indivíduo esteja isolado podendo haver a necessidade de comunicar de algum modo o seu ato criativo. Entende-se que o ato criativo de Beth é a sua imaginação em projetar o tabuleiro no teto, e a comunicação desse ato ocorria para Shaibel, quando jogavam. Desse modo, a Tendência Atualizante estava manifestando como um recurso criativo, visto que Beth não possuía o seu próprio tabuleiro, assim, imaginava-o como uma possibilidade de treinar, elaborar e criar movimentos/lances com as peças. Rogers (2009) sustenta que o processo criativo ocorre diante das circunstâncias da vida, é uma maneira de formular e

\footnotetext{
${ }^{6}$ Ação gabaérgica: é secretada durante o repouso e é capaz de acalmar o cérebro, regulando a atividade dos neurônios.
} 
reformular soluções perante uma adversidade, comenta o autor que o processo reflete no comportamento como uma adaptação ao mundo para sobreviver. Assim sendo, jogar xadrez para Beth também se tornou uma possibilidade, a qual encontrou uma solução para se manter na vida.

No porão do abrigo foi convidada por um colega de Shaibel, frequentador de um clube de xadrez e diretor de uma instituição escolar, a participar de uma demonstração do jogo. Ela jogou com vários garotos simultaneamente em uma escola, e obteve a vitória contra todos. Constata-se a importância de Shaibel no processo de aprendizagem de Beth como um professor/facilitador, além de tê-la instruído com o jogo, acrescentou recursos nos quais ela pôde vivenciar uma experiência fora do abrigo. Rogers (2018) enfatiza que os facilitadores abrem as portas para os recursos externos e a experiência com outras pessoas poderem ocorrer. Mas devido a um episódio, no qual não foi mais permitido politicamente o abrigo administrar os tranquilizantes, Beth passou por abstinência das pílulas, e suas idas ao porão ficaram restritas não se encontrando mais com Shaibel para jogarem xadrez.

Aos 13 anos de idade foi adotada pelo casal Wheatley. O Sr. Wheatley não se comprometeu exercendo os cuidados parentais, e pareceu querer deixar no seu lugar, uma filha para a esposa. Como pretexto, ele viajou a trabalho e não voltou mais para a casa. Alma, a mãe adotiva, mostrava-se deprimida e etilista. Em uma ocasião, Beth se deparou com os medicamentos de Alma, as mesmas pílulas tranquilizantes que teve contato no abrigo. Também encontrou em um posto de revenda, revistas sobre jogo de xadrez com informações de inscrições para um torneio local. Nota-se que Beth se viu diante da oportunidade de poder jogar xadrez se fizesse a inscrição, para isso escreveu uma carta para Shaibel pedindo auxílio financeiro.

Beth se inscreveu no torneio cujo prêmio foi em dinheiro. Chegando ao local, foi subestimada por ser uma garota, concorrendo com jogadores homens experientes, considerada amadora perderia seu dinheiro investido por não possuir pontuações anteriores em torneios. Mas diante das adversidades, Beth questionou as regras, que não a impediam de participar e disse: "vou vencer" (SIC). E venceu. Conforme o tema: b) diante das circunstâncias, iria vencer. Nota-se a Tendência Atualizante manifestando na vida de Beth, por meio do jogo de xadrez, desenvolveu confiança em si mesma e foco no objetivo de vencer.

Nota-se Beth desenvolvendo seu pensamento estratégico e habilidade em solucionar problemas. Filguht (2007) afirma que jogar xadrez aumenta a criatividade intelectual e eleva a autoestima. Assim, identifica-se que Beth não dependeu de uma aprovação masculina para se ingressar no torneio, assumindo a sua experiência de jogadora. Conforme Natalie Rogers (1987) se for da vontade, a mulher deve assumir a responsabilidade da sua própria vida e, assim, se sentirá aprovada. Nesse sentido, a Tendência Atualizante manifestada está em uma autodireção à tendência positiva de uma experiência. De acordo com Feist et al. (2015) é uma força criativa relacionada às necessidades de aperfeiçoamento, expressando confiança de que é possível alcançar determinado objetivo.

Após Beth ser a grande ganhadora do torneio, sua mãe Alma passou a encarar como uma carreira para ambas e tornou-se sua agente inscrevendo-a em importantes campeonatos. Ganhando popularidade, Beth ficou conhecida como uma figura feminina em meio aos 
torneios, predominantemente ocupados por homens. Em uma entrevista, a pergunta que surgiu foi: como é ser uma garota em meio a tantos homens nos torneios de xadrez? Com a resposta de Beth encontra-se o tema: c) "o jogo de xadrez nem sempre é competitivo. Também pode ser lindo" (SIC). O que representa é que Beth não estava necessariamente dando um sentido ao jogo como algo competitivo, embora sempre jogasse para ganhar, e sim como um sentido para sua vida, sendo por meio dele que encontrou oportunidades.

No entanto, ao continuar respondendo à entrevista, constata-se o seu drama pessoal, o qual Beth respondeu que o tabuleiro é um mundo inteiro de 64 casas "me sinto segura dentro dele, se eu errar posso culpar a mim mesma" (SIC). A partir dessa sua fala, identificam-se sentimentos ocultos de sofrimentos com certa profundidade de perfeição. Qual Beth atribuiu um significado ao jogo de ordem e controle, por isso, a sensação de segurança no tabuleiro como algo que faltou na sua infância. Tal hipótese representa a casa que não teve com a ausência dos seus pais.

Distingue-se que Beth, ocupando-se com as estratégias do jogo, não haveria espaço para sentir suas dores emocionais. Em seu nível psicológico averiguou-se que enquanto criança, o jogo também foi uma forma que encontrou de defesa psicológica para lidar com os seus sentimentos de abandono, medo e insegurança. De acordo com Rogers (2009) são sentimentos de fachada, características que os indivíduos mostram para se fechar. Desse modo, Beth validava as suas vitórias pelo controle que exercia das casas no tabuleiro. Algo que talvez inconscientemente buscasse como uma compreensão para a sua vida.

Avançando rapidamente nos grandes campeonatos, desenvolveu obsessão pelas vitórias, um deles na cidade do México e por ocasião, sua mãe Alma relatou que a estavam chamando de jogadora intuitiva/criativa, porque há no estilo de seu jogo alguns lances que não eram previstos, considerados estes os mais bonitos. Beth disse: "às vezes os lances aparecem para mim" (SIC). Identifica-se o que a diferenciava dos outros jogadores eram os seus lances inesperados criativos. Os quais Beth em situações de difícil decisão em determinadas partidas, ingeria as pílulas tranquilizantes e imaginava os lances, mas não diante do tabuleiro físico, e sim por sua percepção visual, projetava o tabuleiro no teto juntamente com as peças para encontrar o melhor movimento delas como possibilidade de solução da jogada e vencer.

Nota-se que Beth continua a repetir o mesmo movimento de projeção do jogo no teto. Parece que para ela, os lances vistos aconteceriam se tomasse os tranquilizantes, como uma forma de ter alucinações. É importante mencionar que o jogo de xadrez desenvolve a imaginação e a criatividade, Filgth (2007) acredita que encoraja o jogador a inevitabilidade, porque há nas partidas quantidades infinitas de combinações que podem ser construídas, visto que a criatividade é um dos principais aspectos do jogo de xadrez, pois aumenta a fluidez, flexibilidade e, principalmente, a originalidade.

Ao referir-se a tal assunto, é relevante destacar, no episódio em que sua mãe Alma comenta sobre a criatividade da xadrezista em jogar. Beth resgata a lembrança de uma narrativa de Shaibel quando a instruía no jogo: "Gente como você sofre dois lados de uma mesma moeda, existe o dom e existe o preço dele [...] você tem muita raiva guardada, tem que ter cuidado" (SIC). Nota-se Beth trazendo do seu passado uma narrativa para a sua 
consciência naquele momento e uma possível disposição de simbolizar os seus sentimentos de sofrimentos que vivenciou quando criança.

A essa disposição de tomada de consciência de Beth, Feijoo (200o) enfatiza como uma atividade da interioridade do indivíduo, na qual há uma carência expressada pela angústia de se conquistar tal consciência. Constata-se que Shaibel identificou no jogo de Beth, a raiva dela quando criança, ou seja, diante de tal prática, ela expressava sentimentos a seu respeito. Para Ekman (20II), indivíduos com raiva informam aos outros sobre um problema seu, visto que para Beth as suas defesas psicológicas pareciam ser o seu estilo de ataques de jogo, no qual expressa a raiva para vencer no jogo, como uma maneira de vencer na vida.

No campeonato do México, Beth perde a partida final para Borgov, um enxadrista soviético imbatível, ficando em segundo lugar no campeonato e novamente encontra-se sozinha. Ao chegar ao quarto do hotel, depara-se com Alma Wheatley, sua mãe adotiva, falecida de suspeita de hepatite. Entretanto, ocorreu-lhe uma lembrança da narrativa da sua mãe biológica. "Um dia você irá ficar totalmente sozinha, por isso tem que dar um jeito de cuidar de si mesma" (SIC). Identifica-se Beth consciente e experimentando uma diferenciação dos seus sentimentos, trazendo novamente do seu passado uma lembrança. Porém, com certa precisão de expressar o sentimento no presente para aceitá-lo com certa responsabilidade. Encontra-se o tema: d) saber cuidar de si mesma (autocuidado). Assim, a Tendência Atualizante manifestava-se por meio dessa narrativa expressando coragem, responsabilidade e autocuidado como uma autodireção positiva, diante das circunstâncias difíceis vividas.

De volta para a sua casa e só, Beth não conseguiu naquele momento dar conta das suas perdas e frustrações (ausência novamente de uma mãe e a perda do jogo no campeonato). Veste-se com as roupas de sua mãe falecida, como uma forma de presentificar a ausência dela, fazendo uso de tranquilizantes, bebidas alcoólicas e cigarros deixados por Alma. Após algum tempo, Beth se lembra de outra narrativa da sua mãe biológica: "É preciso ser uma mulher muito forte. Nunca se esqueça de quem você é” (SIC). A partir dessa narrativa, Beth resgatou a ideia do ambiente seguro, olhando para si e voltando-se para o tabuleiro de xadrez que parece possibilitar a sensação de segurança e domínio. Beth fez uma trégua ao uso das substâncias psicoativas, refinando o seu jogo, melhorando a sua técnica com o auxílio de outros jogadores enxadristas, em específico Benny, que já tinha sua carreira reconhecida.

Benny a apoiou a melhorar a sua técnica de jogo para enfrentar Borgov, o atual campeão mundial. Ofereceu-lhe livros e instruções em sua casa, que era aparentemente um porão. Notam-se as situações de aprendizado de Beth se repetindo, no qual Shaibel e Benny contribuíram no desenvolvimento técnico do jogo, repete-se também ocorrendo em um ambiente de subsolo. Tecnicamente mais bem preparada, Beth viaja a Paris, na tentativa de conquistar o título de campeã mundial. Porém, na noite anterior ao seu último jogo com o adversário Borgov, teve uma recaída, envolveu-se com bebidas alcoólicas. Conforme destaca a Sociedade Brasileira do Exercício e do Esporte (1997), as bebidas alcoólicas afetam o desempenho psicomotor e a capacidade de processamento de informações. Prejudicando tempo de reação e coordenação de mãos e olhos, também afetam aspectos cognitivos de precisão e o equilíbrio corporal. Haes et al. (2010) afirmam que o álcool atua de forma 
semelhante aos benzodiazepínicos ao potencializar a ação gabaérgica e reduzir a resposta glutamatérgica (excitatória). Porém, atua de forma mais acentuada, causando redução da coordenação motora e do raciocínio.

Constata-se nas fases infantil e adolescência da personagem sentimento de perda e abandono. Em suas lembranças nota-se a negligência dos cuidados parentais, ausência do seu pai e o suicídio da sua mãe. Beth também passou por difícil adaptação na instituição do abrigo, diante da realidade que se encontrava (abandono e luto). No abrigo, o jogo de xadrez, encontrado por ela no ambiente do porão, foi um elemento o qual ela se tornou, talentosa e obstinada para uma carreira de enxadrista. Shaibel (zelador), Alma (mãe adotiva) e jogadores enxadristas, como Benny contribuíram como facilitadores, proporcionando a Beth condições nas quais foi possível, por meio do jogo, a busca de uma carreira enxadrista e novas maneiras de se adaptar ao meio.

Embora o jogo de xadrez seja visto como uma atividade de destaque na vida de Beth, foram os próprios sentimentos ocultos expressos silenciosamente no tabuleiro, que se permitiu desvelar sua fachada de defesas psicológicas e suas dores emocionais. Ficando mais evidente em circunstâncias em que vivenciou sofrimentos de perdas e frustrações, levando-a para comportamentos desajustados, comprometendo a sua carreira.

Já a segunda unidade da análise, refere-se ao início da sua fase adulta. Parte do ponto em que a minissérie discorre a continuidade da cena apresentada inicialmente, quando Beth está em Paris, jogando com o enxadrista Borgov. Ela acordou atrasada, tomou as pílulas tranquilizantes, dirigiu-se até o local, com aspecto de ressaca, sentou-se para jogar, nervosa, não se concentrou na partida e perdeu novamente para o mesmo adversário. Ficando evidente que nessa fase da sua vida, seus principais oponentes estão sendo as bebidas alcoólicas e o uso de tranquilizantes.

De volta à sua casa, faz uso de substâncias psicoativas de maneira abusiva entrando em um ciclo autodestrutivo de dependência. Nota-se em Beth uma alienação ao fazer o uso, como um modo de afastar-se das circunstâncias que a angustiam. Identifica-se que para ela a bebida alcoólica proporciona um prazer no momento, mas não funcional, por trazer outras consequências, além de o problema original, como um refúgio dos sintomas produzidos pela sua angústia. Segundo Pires (2020), as bebidas alcoólicas alteram o nível de consciência, comportamento e humor de um indivíduo. Reforçam Haes et al. (2010), que o álcool altera a neurotransmissão dopaminérgica no sistema de recompensa com alto potencial para dependência química.

Assim, identifica-se em Beth o estado de incongruência, passando por processos de desorganização com suas emoções e sentimentos. Em vista disso, é importante mencionar sobre as dificuldades da personalidade, que, segundo Rogers (2018), surgem quando o indivíduo se vê em situações de ameaças, desenvolvendo mecanismos de defesa, muitas vezes enterrada nas camadas psicológicas defensivas. Por conseguinte, Beth se recusa e não consegue participar dos próximos torneios, alterando a sua percepção em relação aos campeonatos. Dispensa um importante patrocínio, decisão da qual vem a se arrepender mais tarde. Verifica-se a sua história de vida em paralelo com a sua carreira de enxadrista, genial e autodestrutiva. 
Por outro lado, assume uma postura de mudanças do seu comportamento, a partir da notícia de que Shaibel havia falecido, ela vai até o seu funeral. Depois, visita o abrigo onde morou, dirige-se ao porão e descobre uma exposição sua de matérias de revistas e recortes de jornais. Lá, encontra desde a sua carta pedindo auxílio para participar do seu primeiro torneio, até as famosas revistas contento matérias nas quais ela era o destaque como enxadrista. Beth reconhece o quanto Shaibel se sentia orgulhoso dela. Emocionada ao ver o material exposto por seu mestre, nota-se Beth sentir a dor do seu passado, mas que essa não a impede de seguir adiante na sua jornada na carreira de enxadrista.

Identifica-se a Tendência Atualizante agindo na sua vida, enquanto no ambiente do porão revive a sua história, sua essência/existência. Nesse aspecto, encontra-se o tema: e) suas experiências estão sendo ressignificadas. Beth, olha para si e para a sua história de conquistas e superações, estando pré-disposta a assimilar sua autoimagem, revista e que pode ser modificada. Salienta Rogers (2018), que a partir disso, o indivíduo tende a ponderar equilíbrio por meio das suas ações, e nessa ponderação, a confiar mais em seu organismo, desenvolvendo-se em direção a uma congruência, entre seu self que sente e seu conceito de si. Assim, nota-se Beth consciente e reflexiva após ter revisitado o porão, o qual forneceu significados para que ela pudesse identificar e perceber uma nova realidade.

Nesse processo da experiência de Beth está o conceito da aprendizagem significativa, em que ela está passando por uma modificação do seu comportamento. De acordo com Rogers (2018) é uma aprendizagem profunda relacionada à existência. $\mathrm{O}$ indivíduo começa a avaliar os seus próprios comportamentos, baseando-se em uma avaliação da sua própria experiência. Considera Rogers (2009), que essa abertura à experiência implica uma tendência do indivíduo para viver uma relação mais aberta, amigável e estreita consigo mesmo. Assim, surge para Beth uma nova possibilidade, um apoio para poder financeiramente estar competindo na Rússia, em busca do seu objetivo.

Ao chegar a Moscou, Beth inicia-se no campeonato. A narração feita é: "Jogadores com títulos de campeões mundiais, não consideram Elizabeth Harmon importante para o padrão deles, mas o que a diferencia é o seu sexo" (SIC). Verifica-se o torneio ocorrendo nos anos de 1967, e o jogo de xadrez associado a um contexto histórico-cultural, de origem guerreira, na qual mulheres não participavam. No entanto, de acordo com Capablanca (1972), a evolução do jogo de xadrez passou por várias modificações nos diversos continentes, mas foi na Europa, que a peça Rainha ocupou posição de destaque no tabuleiro, com movimentos táticos e estratégicos de abertura, inclusive o lance do Gambito da Rainha. É relevante destacar que nessa ocasião do torneio na Rússia, o país estava vivenciando o período da Guerra Fria. E Beth estava lá, uma figura feminina, cidadã americana, com carreira enxadrista representando de forma esportiva/profissional, a possibilidade de se tornar uma campeã mundial.

Beth avança vencendo as partidas e conquistando a posição de finalista. Não faz uso de substâncias psicoativas, descartando as pílulas tranquilizantes. Há também um relacionamento com uma equipe de apoio, são homens enxadristas, os quais Beth conheceu em torneios anteriores. Nos momentos de pausa da partida final, oferecem a ela apoio, liderado por Benny, de forma remota, por meio de telefonemas, passam orientações retratando 
possíveis lances do seu adversário. As partidas são difíceis, mas Beth segue as estratégias que têm, são sólidas e as mantêm.

Beth jogaria com as peças brancas. Precisava se agarrar a essa vantagem com todas as forças. Jogaria o Gambito da Rainha ${ }^{7}$. Benny e ela haviam discutido isso durante horas, meses antes e, finalmente, concordaram que era o modo de agir se ela estivesse com as brancas. Não queria jogar contra a Siciliana de Borgov, por mais que conhecesse bem essa defesa, o Gambito da Rainha era o melhor modo de evitá-la. Poderia segurá-lo se não perdesse a cabeça. O problema é que ele não cometia erros (TEVIS, 2021. p. 288).

Considerando essa possibilidade Beth realizou a jogada. Porém, em um lance do jogo de Borgov, Beth percebe que o raciocínio e as estratégias, anteriormente pensados pela equipe de apoio, não poderiam ser aplicadas. E em um momento de decisão do seu jogo, encontra-se o tema: f) a criatividade leva à vitória. Beth olha para cima e projeta visualmente o jogo no teto do local. Roger (2009) menciona que a criatividade também se trata de uma emergência da ação. Assim, Beth ao imaginar projetando visualmente o tabuleiro no teto, explora as possibilidades e cria mentalmente diferentes movimentos para as peças, que a permite fazer lances inovadores e os reproduz no tabuleiro físico. Conforme Tevis (2021, p. 298), "o peão branco seria promovido a dama e o xeque-mate seria em quatro lances [...] Borgov avançou com seu rei para bloquear o peão. Ela avançou o cavalo, forçando-o a se proteger. Estava acontecendo como tinha visto". Nos últimos lances, Beth move a torre e o seu rei no qual o movimento feito é o da sua vitória, a conquista do título de campeã mundial. "Os aplausos começaram. Beth pegou o rei preto e se virou para o auditório, deixando todo o peso enorme daquela aclamação envolvê-la" (TEVIS, 2021.299).

A minissérie finaliza essa história com uma cena centrada na personagem, na Rússia, vestida com roupas brancas e um gorro em sua cabeça, representando simbolicamente a Rainha Branca do jogo de xadrez. Beth escolhe caminhar sozinha, direcionando-se a uma praça pública para jogar com vários senhores, estes remetendo a Shaibel, indo ao encontro deles e sentando-se para jogar xadrez, também remete ao contexto a ideia de socialização de uma aproximação social com as pessoas.

Assim, considera-se que Beth é uma jogadora criativa, ao desenvolver um processo de (re)elaboração dos movimentos das peças dentro das casas, ao mesmo tempo em que realiza uma atualização no repertório de estratégias. Ficando evidente que não são as pílulas ingeridas que lhe davam habilidades para projetar o tabuleiro no teto, e sim a sua capacidade de imaginá-lo e mentalmente mover as peças. Considera-se também que esse ato criativo de Beth já era realizado desde criança, como uma maneira que encontrou para poder praticar e aperfeiçoar as jogadas com o intuito de vencer do seu mestre Shaibel.

Ao longo da história de Beth, acompanha-se a personagem na busca por compreensão de si mesma, seu drama pessoal de questões emocionais perturbadoras, envolvendo-se com substâncias psicoativas que interferem na sua performance de jogadora. A partir das suas experiências vividas ocorre a mudança para uma regulação organísmica no seu Self.

\footnotetext{
${ }^{7}$ O Gambito da Rainha: é uma jogada feita pelas peças brancas no início da partida, é também uma das inúmeras
} aberturas do jogo de xadrez. 
Considerando que houve pela personagem um reconhecimento das suas potencialidades, avançando nos estágios de mudança de personalidade, abandonando sentimentos incongruentes, adotando uma postura de compreensão dos seus sentimentos, expressando-os mais livremente e com segurança na experienciação das suas tomadas de decisões.

\section{CONSIDERAÇÕES FINAIS}

Este estudo apresenta o fenômeno da Tendência Atualizante manifestado na vida da personagem Elizabeth Harmon da minissérie o Gambito da Rainha. Tal tendência na perspectiva da ACP aborda que os indivíduos tendem a se moverem em direção da sua autorrealização com a capacidade de compreender a si mesmo e se organizarem. $\mathrm{Na}$ visão rogeriana, trata-se de um princípio inerente ao ser humano, uma tendência à atualização organísmica em alcançar um funcionamento harmonioso com o meio.

A despeito do exposto foi realizado o estudo sobre como o jogo de xadrez se tornou uma possibilidade de crescimento e uma forma, na qual Beth encontrou para lidar com as circunstâncias adversas da sua vida, visto a sua curiosidade enquanto criança em aprender sobre o jogo como uma saída das suas experiências dolorosas (ausência do pai, perda da mãe e morar em um abrigo). Contudo, teve como objetivo desvelar o sentido do jogo de xadrez na manifestação da Tendência Atualizante na vida da personagem Beth. Com base nas análises realizadas tornou-se possível acompanhar e compreender a história de vida de Beth, marcada por sentimentos de abandono dos pais, e a sua ascensão na carreira de enxadrista, ao mesmo tempo em que enfrenta comportamentos desajustados de dependência de substâncias psicoativas.

Durante o trabalho foram vistos os aspectos congruentes com a manifestação da Tendência Atualizante agindo na vida de Beth, o jogo de xadrez como resiliência enquanto morava no abrigo, a busca por oportunidades de participar do que viria a ser seu primeiro torneio profissional, considerando que Beth atribuiu ao jogo de xadrez um sentido para a sua vida, descobrindo como uma possível carreira. Ao longo da sua história Beth resgata narrativas de pessoas importantes na sua vida, como uma forma de compressão dos seus sentimentos, seus comportamentos de dependência de substâncias psicoativas, comprometem o futuro de sua carreira de enxadrista. Contudo, as mudanças organísmicas ocorrem após revisitar o porão e reviver suas dores. Assim, suas experiências começam a ser ressignificadas e continua com o seu objetivo em tornar-se campeã mundial. Visto que a sua vitória dependeu da criatividade como jogadora ao mover as peças mentalmente, fazendo escolhas e as experimentando com novas soluções no tabuleiro. Portanto, dado que criatividade é uma capacidade desenvolvida por Beth ao jogar xadrez, capacidade esta manifestada na busca por soluções das jogadas.

Neste estudo foi apresentado como Elizabeth Harmon encontrou soluções para manter-se na vida, por meio do jogo de xadrez manifestava o pressuposto da Tendência Atualizante o qual Beth experenciava seus sentimentos na compreensão de si mesma para alcançar um funcionamento interno mais adequado, em paralelo à sua compreensão de história de vida foi visto a sua capacidade criativa em jogar xadrez. Assim, este estudo pode 
favorecer pesquisas futuras para descrever a criatividade ao longo do processo do desenvolvimento humano.

\section{REFERÊNCIAS}

CAPABLANCA, José Raul. Lições elementares de xadrez. HEMUS, Livraria Editora, São Paulo, i972.

CHAVES, Ana Paula; MENDONÇA, Viviane. Produção de significados: uma proposta de metodologia fenomenológica. Estudos de Psicologia 1997, Vol. 14, ${ }^{\circ}$ 3,65-68. Disponível em: https://www.scielo.br/j/estpsi/a/Dh7tkwV 4 NGn3fhPys5tcYDP/?format=pdf\&lang=pt.

Acesso em: 8 ago. 2021.

EKMAN. Paul. A linguagem das emoções. I. ed. São Paulo: Leya, 20 II.

FEIJOO, Ana Maria L. C. de. A escuta e a fala em psicoterapia: uma proposta fenomenológico-existencial. São Paulo: Vetor, 2000.

FEIST, Jess; FEIST, Gregory J.; ROBERTS, Tomi-Ann. Teorias da personalidade. 8. Ed. Porto Alegre: AMGH, 2015.

FILGUTH, Rubens. A importância do xadrez. Porto Alegre: Artmed, 2007.

FLICK, Uwe. Introdução à metodologia de pesquisa: um guia para iniciantes. Porto Alegre: 697 Penso, 2013.

GIORGI, Amedeo. SOUSA, Daniel. Método fenomenológico da investigação em psicologia. Fim de século edições, 2010.

HAES, Tissina M. de et al. Álcool e sistema nervoso central. Simpósio: Condutas em enfermaria de clínica médica de hospital de média complexidade. Medicina Ribeirão Preto, 2ого. Disponível em: file://C:/Users/gustavo/Downloads/Vista\%2odo\%20\%C3\%8Ilcool\%20e\%20sistema\%2oner voso\%2ocentral.pdf. Acesso em: 30 out. 202I.

HOLANDA, Adriano. A perspectiva de Carl Rogers acerca da resposta reflexa. Rev. NUFEN [online]. 2009, vol.I, n.I, pp. 40-59. ISSN 2175-2591. 2009a. Disponível em: http://pepsic.bvsalud.org/scielo.php?script=sci_abstract\&pid=S2175-25912009000100004.

Acesso em 28 de abril de 2021.

HOLANDA, Adriano. Fenomenologia e psicologia: diálogos e interlocuções. Revista da Abordagem Rev. abordagem Gestalt. v.I5 n.2 Goiânia dez. 2009b. Disponível em: 
http://pepsic.bvsalud.org/scielo.php?script=sci_arttext\&pid=Sı809-68672009000200002. Acesso em: 28 abr. 2021.

HUIZINGA, Johan. Homo Ludens: o jogo como elemento da cultura. São Paulo: Perspectiva, 2018.

IVANICSKA, Rebeca Freitas; ROCHA, Bruna Beatriz da; GUIMARÃES, Ana Maria B. Entre nós há laços: escritos em psicologia humanistas, existenciais, fenomenológicas. Itapiranga: Schreiben, 2021. E-book.

MAIA, Camila Moreira. et al. Um diálogo sobre o conceito de self entre a abordagem centrada na pessoa e a psicologia narrativa. Rev. NUFEN vol.ı no. 2 São Paulo nov. 2009. Disponível em: http://pepsic.bvsalud.org/scielo.php?script=sci_arttext\&pid=S2175-25912009000200004. Acesso em: 3 jul. 202I.

O GAMBITO DA RAINHA. Walter Tevis, Direção: Scott Frank. Produção: Allan Scotto. Produtora: Netflix, 2020 minissérie com sete capítulos (395h).

PENAFARIA, Manuela. Análise de Filmes - conceitos e metodologia(s). VI Congresso SOPCOM, Abril de 2009. Disponível em: http://www.bocc.ubi.pt/pag/bocc-penafriaanalise.pdf. Acesso em: 26 mar. 2021.

REGITAN, Paola. Já ouviu falar sobre inteligência espacial: saiba o que é e aprenda a desenvolvê-la. Blog da Universidade Ibirapuera líderes que inventam o futuro, 202I. Disponível em: https://www.ibirapuera.br/ja-ouviu-falar-em-inteligencia-espacial-saiba-oque-e-e-aprenda-a-desenvolve-la/. Acesso em: 5 nov. 2021.

ROGERS, Carl R. Quando fala o coração: a essência da psicoterapia centrada na pessoa. Porto Alegre, 1986.

ROGERS, Natalie. Mulher Emergente: uma experiência de vida. 4. ed. São Paulo: Martins Fontes, 1987.

ROGERS, Carl R. Terapia Centrada no Cliente. São Paulo: Martins Fontes, 1992.

ROGERS, Carl R. Torna-se pessoa. 6. ed. São Paulo: Editora WMF Martins Fontes, 2009.

ROGERS, Carl R. Um jeito de ser. - São Paulo: E.P.U., 2018.

SAHAGOFF, Ana Paula. Pesquisa narrativa: uma metodologia para compreender a experiência humana. XI semana de Extensão, Pesquisa e Pós-graduação. SEPesq-19 a 23 out.2015.

Disponível em: 
https://www.uniritter.edu.br/files/sepesq/arquivos_trabalhos/3612/879/ı13.pdf. Acesso em: IO mar. 202I

SANTOS, Vania de Carvalho. Xadrez: como instrumento na sala de aula. Versão Online ISBN 978-85-8015-053-7 Cadernos PDE. Curitiba, 2010. Disponível em: http://www.diaadiaeducacao.pr.gov.br/portals/cadernospde/pdebusca/producoes_pde/2009_f afipar_educacao_fisica_md_vania_de_carvalho_santos.pdf. Acesso em: 30 out. 202I.

SARTRE, Jean-Paul. Esboço para uma teoria das emoções. Porto Alegre: L\&PM, 2012.

SARTRE, Jean-Paul. O imaginário: psicologia fenomenológica da imaginação. Rio de Janeiro: Vozes, 2019.

SCHNEIDER, Daniela Ribeiro; ANTUNES, Larissa. A função imaginária no uso de substâncias psicoativo: contribuições de Jean-Paul Sartre. Rev. NUFEN vol. 2 no.. São Paulo jun. 2010. Disponível em: http://pepsic.bvsalud.org/scielo.php?script=sci_arttext\&pid=S217525912010000100005. Acesso em: 30 out. 2021.

SESI, Serviço Social da Indústria. Esgrima e xadrez. São Paulo: Sesi-SP, 2012.

SILVA, M. S. T; TORRES, C. R. O. V. Alterações neuropsicológicas do estresse: contribuições da neuropsicologia. Revista Científica Novas Configurações - Diálogos Plurais, Luziânia, v. I, n.2, p. 67 - 80, 2020. Disponível em: Sociedade Brasileira de Medicina do Exercício e do Esporte. O uso do álcool nos esportes. Rev Bras Med Esporte 3 (3) Set 1997. Disponível em: https://www.scielo.br/j/rbme/a/XRFk7r97mMPB7bcpCFn8VNR/?lang=pt. Acesso em: 20 out. 2021.

SOUZA, Luciana Karine de. Pesquisa com análise qualitativa de dados: conhecendo a Análise Temática. Arq. bras. psicol., Rio de Janeiro, v. 71, n. 2, p. 51-67, 2019. Disponível em: http://pepsic.bvsalud.org/scielo.php?script=sci_arttext\&pid=Si8o952672019000200005\&lng=pt\&nrm=iso. Acesso em: 9 mar. 2021.

TEVIS, Walter. O Gambito da Rainha. I. ed. São Paulo: Arqueiro, 2021.

ZORZANELLI, Rafaela Teixeira et al. Consumo do benzodiazepínico clonazepam (Rivotril ${ }^{\circledR}$ ) no estado do Rio de Janeiro, Brasil, 2009-2013: estudo ecológico. Temas livresCiênc. saúde coletiva 24 (8). Ago. 2019. Disponível em: https://www.scielo.br/j/csc/a/SFJrxL764mB9KJSGHNfvBBk/. Acesso em: 30 out. 2021. 